\title{
EUTHANASIA AND CRYOTHANASIA
}

ABSTRACT: In this paper, we discuss the moral and legal aspects of causing the death of a terminal patient in the hope of extending their life in the future. We call this theoretical procedure cryothanasia. We argue that administering cryothanasia is ethically different from administering euthanasia. Consequently, objections to euthanasia should not apply to cryothanasia, and cryothanasia could be considered a legal option also where euthanasia is illegal.

\section{Introduction}

In 1988, Dr Thomas K. Donaldson was diagnosed with an astrocytoma, a malignant brain tumour with poor long-term prognosis. Being active in the field of cryonics - the low-temperature preservation of dying organisms for a possible future revival and cure - he had already made arrangements for being cryopreserved at death. Since the progression of the tumour would likely destroy parts of his brain before he died, his chances of being preserved with his personal identity intact was set to worsen over time. Hence, in 1990, he sued the Attorney General of the State of California for the right to 
a pre-mortem cryopreservation, so as to improve his chances of a complete preservation. The court found Donaldson had no constitutional right to an assisted death (LaBouff 1992; Pommer 1993), and he lost the case. Fortunately for him, the cancer went into remission and he was later cryosuspended in 2006.

While one might argue that the then-46-year-old Donaldson had already lived a full life, that was not the case with 22-year-old Kim Suozzi. She was diagnosed with glioblastoma in 2011, had a successful fundraiser for her cryopreservation, and was cryopreserved in early 2013 (Alcor 2013; Harmon 2015). In her case, like some other current cryonics cases, she chose to undergo voluntary refusal of food and fluids (VRFF) in order to bring about clinical death, after which she promptly underwent cryopreservation. VRFF is a 1-3 week long process (in Kim's case, it took 11 days) that requires close monitoring and care for the patient, who may become agitated or distressed. It may adversely affect the patient's body state, making cryopreservation more difficult 
What makes these cases interesting is that both Donaldson and Suozzi wanted to die in order to live. In this paper, we will discuss the moral and legal aspects of causing the death of a terminal patient in the hope of extending their life in the future. This could be achieved by cryopreserving a terminally ill person before her body and brain are too compromised, and by subsequently reviving her at a moment in the future when medical technology allows for both her revival and recovery. We will henceforth refer to this kind of procedure involving both euthanasia and cryopreservation in the hope of future revival - as "cryothanasia".

\subsection{The paradox of cryothanasia, ending one's life in order to live} longer

Euthanasia is a medical act aiming at painlessly ending the life of a person affected by unbearable, prolonged and incurable suffering in order to prevent her from experiencing such suffering. Cryothanasia, on the other hand, is a medical procedure aiming at painlessly pausing the life of a person affected by unbearable, prolonged, and incurable 
suffering in the hope of one day being able to resume and extend her life ${ }^{1}$.

As noted by David Shaw in his article in Bioethics (2009) and by Ole Martin Moen in his article in the Journal of Medical Ethics (2015), cryonics presents a paradox for many anti-euthanasia arguments. Extending health and life is the goal of medicine, and typically such arguments claim euthanasia is contrary to these goals. Cryonics would work best if euthanasia were available, and so the patients want euthanasia to extend life. One can either accept euthanasia for cryonics purposes as being in line with the arguments against normal euthanasia, or have to argue that it is impermissible for some other reason. This paper will explore these possibilities.

\footnotetext{
${ }^{1}$ It may be that people with terminal diseases feel less scared of choosing cryothansia than euthanasia. Hence, they opt for cryothansia a few months (or perhaps years) before they would otherwise have opted for euthanasia, for instance because they want to preserve their body before cancer spreads through many organs, or because they overestimate the chances that cryonics works in the future. In this case, the patient would most likely lose those final months (or years) of her life in which she is already in pain or the quality of her life has dropped because of her disease. It seems to us that, although the odds of cryonics working are very low at the moment, it would not be irrational or unjustifiable to gamble a few months of disease-stricken life for a better preserved body that might allow one to live for many years in the future.
} 
The goal of this paper is to show that administering "euthanasia" and subsequent cryopreservation is ethically different from administering euthanasia, and thus that objections to euthanasia should not apply to cryothanasia.

\subsection{Cryonics procedures}

The idea that cryonics is feasible is based on four core assumptions (Best 2008): (1) low temperature can slow metabolism, and at sufficiently low temperatures chemical change is essentially stopped on the timescale of centuries. (2) Ice formation, which tends to disrupt microstructure in the body, can be reduced or eliminated through the right vitrification compounds. (3) Legally dead does not necessarily imply irreversibly dead in all cases, but only in cases of patients declared dead according to the brain-death criteria. In other cases, the dying process is fairly drawn-out, with tissue breakdown occurring on timescales of hours to days (Best 2012). (4) Damage due to the lowtemperature preservation and clinical death that is not reversible today is theoretically reversible in the future. 
The two first assumptions are fairly uncontroversial, being at least testable using standard science. The two later assumptions, on the other hand, are hard to test. There is historical evidence (such as the invention of (PR) of medical states once regarded as irreversible death which have later become treatable (if serious) conditions, and of medical advances that have turned many previously incurable conditions curable in ways that were inconceivable just a few years prior. For the purposes of this paper, what matters is that people can have a rationally justified belief that cryonics can work.

Currently, cryonic preservation procedures begin after legal death has been pronounced. Once this has occurred, medications to maintain sedation, reduce metabolism, prevent blood clotting, reduce ischemia/reperfusion injury, etc. are administered, while blood circulation and respiration are restored as far as possible to keep tissues alive. The patient is cooled using ice water to bring down body temperature below $10^{\circ} \mathrm{C}$, at which point perfusion with vitrification solution begins. Temperatures are then gradually lowered until the body reaches a storage temperature of $-196^{\circ} \mathrm{C}$. At this point, nearly 
indefinite storage in liquid nitrogen with no change is possible (Best 2008, Best 2012).

What is relevant for this paper is that the cryopreservation process requires coordinated medical treatment that can only legally occur after death has been pronounced, that the treatment would be placing the patient in a state that by current standards is dead, and that the cryopreservation and general bodily state would be better (by the standards of the above assumptions) if the process could be initiated before disease progression causes the body to deteriorate too far.

\subsection{Definitions of death}

Regardless of the definition of death one might refer to, the common ground to all definitions of death is that it is an irreversible process ${ }^{2}$. Death necessarily implies the irreversible cessation of one, some, or all of the following functions or properties: 1) functioning of the entire brain, including the brainstem; 2) brainstem function; 3) the capacity for consciousness; 4) functioning of the circulatory and respiratory systems.

${ }^{2}$ See (Hershenov 2003) for a dissenting view. 
However, the aim of cryopreservation is to actually turn the irreversible event or process we call death into a reversible one (Eberl 2008, Shaw 2009). So regardless of how one defines death, the cryopreservation and (hoped) subsequent revival of an individual would turn the event/process of at least some current deaths into a reversible event/process.

Instead of relying on than the standard clinical definition of death (i.e. clinically irreversible cessation of brain or circulatory and respiratory functions), cryonics supporters often argue from a different account: namely that of information-theoretic death (Merkle 1992). According to the information-theoretic account of death, one is not dead as long as information encoded within one's brain is not corrupted to the point that it can never be recovered. A person could be dead according to the clinical account of death, yet still be alive insofar as the information in their brain has not been damaged beyond the point that it could not in principle be retrieved in sufficient quantities for restoration in a functioning substrate. 
The problem in the clinical setting is that it is rarely clear when the state is truly irreversible rather than irreversible given current methods, but practically the latter can be estimated in most cases (Whetstine et al. 2005). An even more vexed issue is whether enough information persists through the dying and cryopreservation processes to allow a meaningful recovery. Discoveries that frozen cat brains did show electrical activity when thawed (Suda, Kito \& Adachi 1966), that LTP persists in tissue slices (Fahy et al 2013), and that nematode worms retain long-term memories after revival (Vita-More \& Barranco 2015) is evidence that significant information remains (Darwin 2011), but it is not known for certain if that is enough to maintain personal identity.

These are empirical questions that ought to be answered in order to assess whether cryonics is a worthwhile means of preserving a person, or whether it turns out to be an expensive way to keep a body or a brain intact over time. These questions will only be answered if and when successful cryonic revival is (hopefully) demonstrated. At that 
point, the ethical issues of whether cryopreserved patients are dead and whether cryothanasia is permissible will presumably be resolved once and for all.

\section{Cryothanasia as opposite to euthanasia}

People who are affected by a severe or terminal disease, or experiencing unbearable pain can, in places where it is legal, ask physicians to bring their suffering to an end. This can be done by either stopping treatments intended to extend their lifespan (by weeks, months, sometimes years) or to give them a medication that will cause their death.

Severe physical and/or psychological suffering is what normally motivates patients to request euthanasia. The goal of euthanasia, it can be argued, is not to hasten death, but to stop unbearable suffering. Patients ask for euthanasia when they think that their suffering is unbearable, and the therapies available are inadequate. Euthanasia becomes the only measure that can be taken in order to stop their suffering, and death becomes the only alternative to suffering. 
However, patients would most likely be happy to avoid euthanasia, if the option of both avoiding physical/mental suffering and avoiding death were given to them. Unfortunately, even though medicine has reached impressive results in the last decades when it comes to extending lives and increasing wellbeing, not all illnesses are curable and some still cause unbearable suffering. Since the primary goal of euthanasia is to bring suffering to an end, with death being a "mere" side effect of achieving this goal, it is plausible to argue that removing this side-effect from euthanasia would be desirable.

Cryothanasia would offer the option of ending the patient's suffering by inducing a cryopreservation, which is a state of (hopefully) reversible biostasis. It achieves the positive goal of euthanasia (ending suffering) without its negative instrumental side-effect (permanent cessation of life). Even if it turns out to cause information-theoretic death, the intention is clearly to extend life. 


\section{The badness of death}

There are different reasons why people do not want to die, and they vary according to the religious or philosophical framework one individual operates under. However, there are also some objective harms of death which cryopreservation - if it worked, and if revival were possible - could overcome.

\subsection{End of experience}

One reason death is bad is that it marks the end of all experiences one might have. Assuming that having experiences is better than not having experiences (unless those experiences contain mostly or only suffering), then death is bad.

For the few individuals who have already undergone cryothanasia, the alternative would have been unbearable suffering followed by (irreversible) death. So although they most likely would have preferred to keep living their lives, surrounded by the love of their friends and family in a world they were familiar with, they did not have that choice. So although life is arguably better than cryopreservation, 
cryopreservation is better than euthanasia or death, because it would - at least in principle - allow people to restart having experiences.

\subsection{Loss of identity}

Another objectively bad aspect of death is the loss of connectedness with previous selves or loss of personal identity. Death is by far the most common cause of loss of personal identity, but it is not the only one. Certain psychiatric disorders, severe brain damage, and dementia can also cause loss of identity.

At the moment, we do not know if people revived after cryopreservation would experience a dramatic change in personal identity. It may be that they would experience a partial or total loss of identity. If a total loss of identity were to occur, one could argue that cryopreservation would not have worked and the outcome would be similar to death for the cryopreserved. If I cryopreserve my body and, upon being revived, cannot remember anything about my life prior to being cryopreserved, then it is reasonable to argue that my body has been revived but that the person I used to be is dead. Indeed, we think that, strictly speaking, individuals in a persistent vegetative state 
(PVS) are dead even though their body functions are intact. To extend our lives we do not need just our body, but mainly our personal identity.

People who are experiencing a slow loss of their identity due to Alzheimer's disease or similar conditions might ask to be cryothanized in order to limit the damage to their identity caused by the disease. A person in the early stages of Alzheimer's might ask to be euthanized because she does not want to suffer the loss of identity that inevitably follows from the disease. However, the question about whether people affected by Alzheimer's should obtain euthanasia is an open one (Hertogh et al 2007). In a sense, if death is the irreversible loss of one's identity, the person affected by Alzheimer is going to die when the damage caused by the disease becomes so extensive that the person loses significant portions of her identity, or even her whole identity. Death is currently the only option for Alzheimer's patients who want to avoid this loss of identity, as the therapies developed so far can only slow down the process, but they cannot stop it. 
However, if it turned out that people could go through the cryopreservation process without losing their identity, then people affected by Alzheimer's disease, dementia, and similar conditions could choose cryothanasia as an alternative to both euthanasia and loss of identity. Assuming that a person affected by Alzheimer's is morally entitled (we are not interested in legal entitlement for now) to obtain irreversible euthanasia, then it seems reasonable to argue that she should be entitled to potentially reversible cryothanasia.

If cryopreservation successfully preserves bodily functions but not personal identity, it is a partial failure. However, this is not a sufficiently bad outcome to be considered worse than death. In the case of a person who is affected by a terminal disease, the experience of waking up with no memory of who they were, and of what happened previously in their lives, would not be much different from having amnesia. This new person would presumably have a life worth living despite lacking a connection to the past person. In a sense, the person who lived the old life would be dead. However, the body - the particular combination of genetic and environmental traits that made 
that person - would still be there, and there is a chance that this genetic and physical continuity would result in the newly revived person resembling the old person in potentially significant ways. In any case, it seems to us that the connection with the previous self would be stronger in case of cryothanasia followed by loss of memories than in case of conventional death. It is reasonable to argue that for some people, surviving with amnesia is a better option than dying, and these same people would prefer cryothanasia with loss of information over conventional death.

\section{Standard arguments against euthanasia}

In the following sections, we will show that cryothanasia successfully avoids most arguments against euthanasia. However, we will not discuss the actual strength of each argument.

Life is a gift from God

In opposition to euthanasia, it is often argued that we must respect our own value as human beings because life is a gift from God, and cutting it short in order to escape suffering disrespects the value of this gift. 
However, in the case of cryothanasia, the choice is between letting life end and continuing the struggle to survive. Even though there is a risk that cryonics fails, there is no reason to believe that not trying would be respectful of the value of life. Indeed, it may be argued that attempting cryonics is proof of one's great appreciation of the gift of life - one appreciates it so much that one goes to great lengths in order to preserve it. It could be compared to undergoing risky surgery in order to avoid certain death.

\subsection{Ethical objections}

Euthanasia is sometimes considered morally impermissible because it is an act that causes death, whereas omissions causing death (in the context of patients affected by terminal conditions and for whom certain treatments would be considered futile or too burdensome) are usually considered morally acceptable. However, cryothanasia is an act that causes certain death to become an uncertain possibility of death. It would be better if an act could be undertaken to bring about 
health, but if such an act is not possible, then reducing the certainty of death is certainly an improvement ${ }^{3}$.

In the case of classic euthanasia, the doctrine of double effect doesn't justify the intervention because even if the goal (relieving suffering) is beneficial, the act itself (killing) is not morally neutral or good. But in the case of cryothanasia, the goal (extending life) is beneficial and the act (a temporary cessation of life processes) is intended to be neutral, so there is a relevant asymmetry with standard euthanasia. One can still argue that the good is not proportionate to the risk involved in the cessation, which is itself unintended and unwanted; we will deal with this objection in section 5.2 and 6 below. Another approach would be to argue that there are good reasons to treat temporary cessation of life processes as inherently bad, but it is hard to imagine where the inherent badness of temporary cessation of life would derive from, and why it would not apply to the relevantly similar case of medically induced coma or hypothermic circulatory arrest.

${ }^{3}$ For an interesting argument based on an adaptation of Pascal's Wage to cryonics see Shaw 2009. 


\subsection{Religious objections}

A common objection to cryonics is that "cheating death" amounts to "playing God". However, this argument must be based on the assumption that cryopreservations are against God's will (in fact, some have presented theological arguments in favour of cryonics, e.g. (Montgomery 1968)). Conversely, if lifespan has been divinely determined and must be accepted, then all life-extending or lifesaving treatments amount to playing God. The religious objector to cryothanasia needs to articulate how is this radically different from what is done in Intensive Care Units (Bridge 2015), or how cryonics is different from any expensive treatment aimed at prolonging the life of patients by any number of years.

While some religious people can see suffering as a positive value (e.g. Pope John Paul II: Salvifici Doloris, 1984), they tend to regard the relief of suffering as a good thing, provided it is not achieved by eliminating the suffering individual (as in the case of euthanasia). Cryothanasia is not primarily about relieving suffering, but about avoiding death. While some religious and secular views regard death as having positive value, whether intrinsically or instrumentally (i.e. as a means 
of getting to an afterlife), they rarely consider it positive to seek death. If one has a chance of going on living and leading a decent life, it seems unreasonable not to take it ${ }^{4}$.

\subsection{Practical medical ethics objections}

One of the main arguments against medically assisted euthanasia is that doctors have the duty to heal diseases and restore health, and according to the Hippocratic Oath, they should not kill people under any circumstance. According to this view, then, doctors should not practice euthanasia, and where euthanasia is legal, they should have the right to refuse to perform euthanasia or to facilitate euthanasia.

In a sense, cryothanasia would cause clinical death, but it would not cause information-theoretic death - and if cryonics works, this would actually extend the lifespan of the patient. Doctors participating in cryothanasia would not violate the principle according to which they

\footnotetext{
${ }^{4}$ Cryonics patients might not learn any lessons from terminal suffering, but if successful they get a new life to learn in, plus what was certainly a life-changing brush with death.
} 
should never cause the death of their patients. In these cases, disease or aging would kill the patient anyway within a relatively short time. What the doctor can do is to give the patients access to a procedure that gives them a (remote, but non-negligible) chance to pause and (hopefully) resume their life in the future. The doctor's intention in the case of euthanasia is also remarkably different from that of cryothanasia: in the first case, the life-stopping process (euthanasia) is motivated by the intention to end suffering by causing death; in the second case, the life-pausing process (cryothanasia) is motivated by the intention to avoid death.

Another common argument against euthanasia is that if people ask to die because they are suffering (either physically or psychologically), we should provide them with better palliative care, rather than helping them to die. In this sense, request for euthanasia is the result of inadequate therapies aimed at reducing suffering, and if people could avoid suffering, they would not ask for euthanasia. Is palliative care also a better option than cryothanasia? Cryothanasia does not exclude palliative care, but in order to maximize the chances that an 
individual would be successfully revived in the future, palliative care should not be administered to the point at which the individual is too damaged. The person asking for cryothanasia would not require it out of lack of proper palliative care, and lack of therapies to managing pain, but out of desire to extend their life-span - although in a more remote future.

In countries where euthanasia is not legal, the only available alternative for a suffering patient may be voluntary refusal of food and fluid (VRFF) - a form of passive euthanasia involving long, drawn-out suffering. Given that cryothanasia (as we argue) would have to be a legal option in countries where euthanasia is not, allowing cryothanasia would reduce the need for VRFF and thereby reduce unnecessary suffering.

Another common argument is that euthanasia gives doctors a form of power over life and death that is improper. It may be true that doctors often have too much power over their patients, and that the 
relationship between patients and doctors is an unbalanced one. However, it is not obvious that euthanasia, and even more cryothanasia, are a particularly good example of an intervention where doctors exercise too much power. Normally, doctors recommend the therapy that they believe is in the best interest of the patient, given the diagnosis and the therapeutic options available. The patient can then follow the recommendation or refuse the treatment. However, in the case euthanasia, and even more so cryothanasia, the patient takes the initiative and asks the doctor to intervene. Cryothanasia, in particular, deals with cases where the patient has actively chosen this option against other more common ones.

It can still be argued that cryothanasia is an irreversible step in the present. Once performed, the only possibility of future life is that cryonics will work - whereas without cryothanasia, there might be other options. Hence a sceptic may argue that it should be put off until death naturally occurs, whereupon cryonics is a last-ditch hope. However, this ignores the cost of suffering and/or mental degradation. 
Irreversibility does not trump other considerations; otherwise, irreversible surgery such as appendectomy would be unacceptable.

\subsection{Psychological/cultural objections}

Euthanasia can be seen as a desire to control life or the world to an unhealthy degree. It is not hard to imagine cryonics being subject to the same objection. However, cryothanasia represents a radical surrender of control to future generations. While the patient may be choosing to end their current lifespan in a particular way, her eventual state is in many ways more open than dying conventionally ${ }^{5}$.

It is sometimes argued that cryonics denies death, and that this is psychologically or ethically unhealthy. However, the practical reality of cryonics actually makes the possibility of death a far more salient aspect of life. Having to plan for one's terminal stages and being aware of the limited chances of a proper cryopreservation due to unavoidable accidents seems to be the very opposite of denying death.

\footnotetext{
${ }^{5}$ Indeed, this might be a reason many people do not sign up for cryonics.
} 
Standard slippery slope arguments against euthanasia involve the prediction that allowing euthanasia would lead to cultural shifts towards a greater acceptance of unethical activities (and that ethics and politics will be unable to prevent this process). In the case of cryothanasia, it might be imagined that it could be undertaken for even milder conditions or for frivolous reasons. We give a principled limit to when it is rational in section 6 below.

\section{Arguments specific against cryothanasia}

Perhaps the most likely argument against cryothanasia is the "weirdness argument". According to this view, cryonics is weird, and hence cryothanasia is impermissible. Expressed in this form it is clearly fallacious, but we have little doubt that unease with exotic medical practices contributes to intuitive rejection and motivates accepting weak ethical reasoning. Still, some experimental and disquieting medical procedures, such as heart transplants, have gone from weird to normal. Moreover, some motivations regarded as weird outside groups holding them have become accepted as morally valid reasons for (not) performing medical interventions, despite diverging 
strongly from what mainstream medical ethics would allow (e.g. circumcision, refusal of blood transfusions). Stronger ethical arguments are thus needed to reject cryothanasia.

\subsection{The unlikelihood argument}

Perhaps the strongest argument against cryothanasia is that cryonics is unlikely to work, and so allowing cryothanasia is equivalent to allowing people to jump off a particular cliff in the belief that they will become immortal. People would get cryothanasia in the hope of extending their lifespan, but they would just end up being cryopreserved at very low temperature for a very long time, something not substantially different from being buried or cremated.

The problem is that the likelihood of cryonics working is very hard to estimate. Unlike a weather forecast or an estimate of future computing power, determining whether revival is even physically possible is unknown and may remain so until close to the point where it is successfully achieved. Thomas Donaldson wrote: 
“There is an IRREDUCIBLE UNCERTAINTY which is basic to cryonics, not merely an adventitious consequence of our ignorance about how memory is stored." (Donaldson 1976)

The means by which cryonics can successfully be achieved remains unknown, although there is no shortage of sketches and plausibility arguments. Indeed, even if we are in a state of ignorance or uncertainty we can often make sensible judgements about likelihood based on expert judgements. However, in the case of cryonics we also have strongly divergent views among potential experts, and even disagreement of who is an expert (i.e. do the critical views of a doctor who has not studied cryonics in detail outweigh the possibly biased positive views of a private cryonics provider?). This complicates any arguments based on an activity having such low chances of success that the large benefits of success cannot outweigh the harms of failure.

In cases of high uncertainty, we might still regard the potential harms as sufficiently large to make the action impermissible regardless of the value of success. In the case of "standard" cryonics, given that no more 
harm than the one already occurring because of the disease can take place, then it is always worth taking the risk no matter how low the chances of success. But cryothanasia would be a different case from cryonics performed upon natural death ("standard" cryonics), because it would involve a certain shortening of the "natural" lifespan. In the case of cryothanasia, then, one would have to weigh up the possibility of enjoying many years of life in the future if cryonics succeeds against the certainty of losing some months or years in order to be cryopreserved before their brain/body are corrupted (we discuss this point in detail below).

\subsection{Futility and experimentalness}

A related issue is the possibility that cryothanasia may be a futile treatment, since it may end up merely preserving a body at very low temperatures - something that doesn't appear to be worth investing money and other resources into. However, it is not obvious that cryothanasia is a futile treatment.

A treatment can be considered futile when the benefits it brings about about are not proportionate to the cost of the treatment, or when the 
treatment does not improve the condition of the patient - either because the treatment buys too little time to the patient (a few hours or days), or because the quality of the time bought is extremely low (a treatment that would leave a person severely disabled would be futile).

Interestingly enough, uncertainty about the possible success of cryonics makes it potentially the most effective intervention, or a very futile one. The fact that we are so uncertain about the success of cryonics makes it irrational to judge it on futility grounds. Futility is commonly defined as a situation where the evidence shows no significant likelihood of the treatment conferring a significant benefit. Here there is an absence of evidence.

When a form of treatment lacks empirical evidence, it is considered experimental treatment. So given the uncertainty about the success of cryonics, we have to consider this treatment an experimental one, not a futile one. 
Cryothanasia could be considered an experimental treatment for patients affected by conditions that are currently untreatable. The right to use experimental drugs which have passed phase I testing but have not yet been approved by the FDA is protected by the so called "Right to try laws" which have been introduced in 27 US states over the last two years. One could argue that the right to cryothanasia should be protected by the same laws, although unlike post-Phase I experimental treatments, it is not possible to assess the probability that cryonics will be successful. However, what is relevant in the context of people affected by terminal diseases, and for whom no other treatment is available, is that the probability is still greater than 0. From a moral perspective, the use of experimental treatment is indeed justified on the basis that it is the only alternative to die within a short time for some patients, so it is in their best interest to use a potentially unsafe treatment in order to have a chance to survive.

Opponents of experimental treatments for severely ill patients claim that offering this option to them implies coercion and exploitation. However, people choosing to undergo cryothanasia make their 
decision autonomously. For cryothanasia to be coercive and exploitative, the patient would have to be in a situation where other options were available, yet she were nudged to choose the least ideal option over better ones by being promised a reward of some sort. This is clearly not the case of people who choose to be cryopreserved, as no incentive or reward is involved, and no better option is available to the patient.

Moreover, as with most experimental treatments, the probability that it could work is affected by current activities (including whether people are suspended or not) (de Wolf 2009): The more we conduct research on cryonics, the more likely it is that cryonics will become a viable option - so the plausibility of cryonics in the future depends on our investments. Thus, prophesising that cryonics will not work and cryothanasia will be a futile treatment appears self-fulfilling: since people think cryonics will not work, they will not conduct research on it and - as foreseen - it will not work. 
Another sense in which cryothanasia could be considered futile even if it worked is that, if the person has lived long enough, then it is futile to invest resources in treatments to extend their lives. For instance, one might say that a treatment aimed at extending the life of a 90 year old is futile, regardless of the kind of treatment one is using. However, there must be a limit to this. What if a 90 year old needs an aspirin in order to survive? It seems unlikely that then the treatment should be considered "futile", given the fact that the treatment is extremely cheap. But one would say that using intensive care to extend the life of a 90 year old is futile because intensive care treatments are expensive. Where does cryothanasia stand in this spectrum? It is (equally or even more) expensive than brief intensive care, but the gain could be quite enormous.

\subsection{Resources argument}

It might be argued that allowing cryothanasia uses up resources that could otherwise have been used for other people's treatment.

In practice, cryothanasia is likely to drastically shorten end-of-life care (consider that VRFF requires weeks of hospice care) and hence free up 
resources. While it is true that some resources are used for the preservation process, this is a one-time cost today paid for by the patient (rather than public money) and employs private cryonics staff rather than medical staff. The cryopreserved state itself is very cheap, involving little more than biweekly liquid nitrogen refills. For the argument to work, cryonics needs to be both far more popular than it is today, and strongly compete with other medical activities.

\subsection{Legal status}

A cryonics patient is legally dead, their body currently treated as an anatomical donation by the cryonics company. May not future revival lead to them become legal non-persons?

This is a weak ethical argument against cryopreservation, since it actually happens that people declared dead in absentia are revived. Reversing the ruling may be an extensive process, but these legally dead people can still function in society. The risk of cryonics patients becoming non-persons is far outweighed by their interest in being alive. 


\section{The rational limits of cryothanasia}

Where lie the limits for the permissibility of cryothanasia for informed, consenting adults? We have argued that cryothanasia is permissible in the case of people who have a terminal condition. But since ageing is a terminal condition, does this mean everybody qualifies? What about somebody with an expected shorter lifespan than the mean population, or a healthy person yearning for the future?

Essentially, cryothanasia for a person near death is a gamble of a small number of Quality Adjusted Life Years (QALYs) versus a lowprobability gain of many QALYs. Traditional cryonics is a gamble of zero QALYs versus a potential gain ${ }^{6}$. Whether cryothanasia is rational depends on whether the ratio (remaining QALYs)/(potential QALYs) is less than the estimated probability of success.

People who proclaim zero success probability are likely overconfident (Ord, Hillerbrand \& Sandberg 2010). But even a 1\% success probability and a mere extra 10 years of good life implies that it is rational to

${ }^{6}$ For a discussion of ordinary cryonics as form of Pascal's Wager see Shaw 2009. 
perform cryothanasia when less than a tenth of a QALY remains, which in actual clinical practice might correspond to a month or more of remaining life. Risking too many life-years may be irrational: if we assume an extra healthy lifespan of 80 years post-revival but only $1 \%$ chance of this occurring, then at most 8 years of life should be risked (given normal risk aversion most people will hardly go that far).

This is basically Glover's maximizing policy: "Other things being equal, we ought to intervene in a non-random way if the result will be a smaller loss of life." (Glover 1990).

This implies that the appropriate time for cryopreservation is a function of different elements, such as average life span and particular conditions of a person. Someone who has cancer at a young age would thus qualify: although far below her life normal span, because there are other conditions shortening her life. A healthy 90-year old would qualify for the opposite reason. A middle-aged person who is merely ageing or yearning for the future would not be qualified, unless there 
was a general agreement that the success probability and post-cryonic lifespan would be high enough.

Practical policy will be a trade-off between society's evaluation of the chances and patients' right to seek unproven or uncertain treatment ${ }^{7}$. This is likely to make cryothanasia unavailable for healthy young people, while reasonable for clearly terminal conditions like that of Kim Suozzi. Intermediate cases like Thomas Donaldson or someone with incipient dementia may be more contested, but developing a consistent policy does not seem impossible.

\footnotetext{
${ }^{7}$ There is a valid problem with estimating how much life could be gained: medical technologies allowing revival from a cryopreserved state (plus a presently terminal condition) almost certainly imply very advanced cell and tissue repair. Optimists may hence estimate that far more than 80 years could be gained by performing cryothanasia (potentially with more life quality per year than current healthy life-years), essentially justifying cryonics with nearly any probability of success and cryothanasia at nearly any age. This is similar to Nick Bostrom's "Pascal's mugging" scenario (Bostrom 2009). However, since the probability of the optimist being right about the value estimate is less than $100 \%$, if they are rational they should take other's more sceptical opinions into account. Also, staying alive has a high likelihood of being a safer way of getting to the future than undergoing cryonics.
} 


\section{ACKNOWLEDGMENTS}

The authors would like to thank Timothy Campbell, Ben Levinstein, Adrian Rørheim, Owen Cotton-Barratt, Aschwin de Wolf and two anonymous reviewers for their useful comments.

\section{References}

Alcor (2013). The Cryopreservation of Kim Suozzi. http://www.alcor.org/blog/thecryopreservation-of-kim-suozzi/ (Accessed on 2016-04-25)

Best, B. P. (2008). Scientific justification of cryonics practice. Rejuvenation research, 11(2), 493-503.

Best, B. P. (2012). Vascular and neuronal ischemic damage in cryonics patients. Rejuvenation research, 15(2), 165-169.

Bostrom, N. (2009). Pascal's mugging. Analysis, anp062.

Bridge, S.W. (2015) Why a Religious Person Can Choose Cryonics. In Preserving Minds, Saving Lives: The Best Cryonics Writings from the Alcor Life Extension 
Foundation, Eds: de Wolf, A. \& Bridge S.W. Alcor Life Extension Foundation, Scottsdale AZ. http://www.alcor.org/Library/html/frozensouls.html

Darwin, M. (2011) Does Personal Identity Survive Cryopreservation? http://chronopause.com/chronopause.com/index.php/2011/02/23/does-personalidentity-survive-cryopreservation/ Accessed 2016-04-25.

Donaldson, T. (1976) A Brief Scientific Introduction to Cryonics. http://www.alcor.org/Library/html/DonaldsonBrief.html

Eberl, J. T. (2008). Potentiality, possibility, and the irreversibility of death. The Review of Metaphysics, 61-77.

Fahy, G. M., Guan, N., de Graaf, I. A., Tan, Y., Griffin, L., \& Groothuis, G. M. (2013). Cryopreservation of precision-cut tissue slices. Xenobiotica, 43(1), 113-132.

Ganzini, L., Goy, E. R., Miller, L. L., Harvath, T. A., Jackson, A., \& Delorit, M. A. (2003). Nurses' experiences with hospice patients who refuse food and fluids to hasten death. New England Journal of Medicine, 349(4), 359-365.

Glover, J. (1990). Causing death and saving lives: The moral problems of abortion, infanticide, suicide, euthanasia, capital punishment, war and other life-or-death choices. Penguin UK. P. 8 
Harmon, A. (2015) A Dying Young Woman's Hope in Cryonics and a Future. New York Times, Sept 122015.

Hershenov, D., 2003. The problematic role of 'irreversibility'in the definition of death. Bioethics, 17(1), pp.89-100.

Hertogh, C.M., de Boer, M.E., Dröes, R.M. and Eefsting, J.A., 2007. Would we rather lose our life than lose our self? Lessons from the Dutch debate on euthanasia for patients with dementia. The American Journal of Bioethics, 7(4), pp.48-56.

LaBouff, J. P. (1992). He Wants To Do What-Cryonics: Issues in Questionable Medicine and Self-Determination. Santa Clara Computer \& High Tech. LJ, 8, 469.

Merkle RC: The technical feasibility of cryonics. Med Hypotheses 1992, 39:6-16.

Moen, O. M. (2015). The case for cryonics. Journal of medical ethics, medethics-2015.

Montgomery, J. W. (1968). Cryonics and Orthodoxy. Christianity Today, 12, 816.

Ord, T., Hillerbrand, R., \& Sandberg, A. (2010). Probing the improbable: methodological challenges for risks with low probabilities and high stakes. Journal of Risk Research, 13(2), 191-205. 
Pommer III, R. W. (1993). Donaldson v. Van de Kamp: cryonics, assisted suicide, and the challenges of medical science. J. Contemp. Health L. E Pol'y, 9, 589.

Kim's case, D., (2009) Cryoethics: seeking life after death. Bioethics, 23(9), pp.515-521.

Suda, I., Kito, K., \& Adachi, C. (1966). Viability of Long Term Frozen Cat Brain In Vitro. Nature, 212, 268-270.

Vita-More, N., \& Barranco, D. (2015). Persistence of Long-Term Memory in Vitrified and Revived C. elegans. Rejuvenation research, (ja).

de Wolf, A. (2009). 5 dangerous ideas about cryonics. Institute for evidence-based cryonics January 20, 2009 http://www.evidencebasedcryonics.org/2009/01/20/5dangerous-ideas-about-cryonics/

Whetstine, L., Streat, S., Darwin, M., \& Crippen, D. (2005). Pro/con ethics debate: When is dead really dead?. Critical Care, 9(6), 538. 